\title{
Solvent Extraction of Silver from Nitric Acid Solution with a Mixture of LIX84I and PC88A
}

\author{
Pan-Pan SUN, * Byoung-Jun MIN, Hyoung-Il SONG and Sung-Yong CHO \\ Department of Environment and Energy Engineering, Chonnam National University, \\ Gwangju 500-757, Republic of Korea \\ (Received April 6, 2015; Accepted October 5, 2015)
}

The solvent extraction of $\mathrm{Ag}(\mathrm{I})$ from nitrate solutions has been studied using a mixture of LIX84I and PC88A. The mixture showed significant synergism at a LIX84I/PC88A ratio of 0.8:0.2. In order to identify the extraction reaction, the effects of various parameters, such as the equilibrium $\mathrm{pH}$ value and extractant concentration, were studied based on the slope analysis method. From stripping studies, $3 \mathrm{~mol} / \mathrm{L}$ of nitric acid was found to be the best stripping agent. This mixed extractant can be applied for the separation of $\mathrm{Ag}$ from a nitrate solution containing $\mathrm{Ca}, \mathrm{Si}, \mathrm{Al}, \mathrm{Re}$, and $\mathrm{Ni}$.

\section{Introduction}

Silver is a precious metal that plays significant roles in many facets of human life [1]. It has been widely used in aesthetic, industrial, and technical fields due to its unique physical and chemical properties. Recently, its technical applications have been extended to producing brazing alloys, electrical and electronic products, photographic paper and film, and catalysts. In particular, $\mathrm{Ag}$ is the active species in $\mathrm{Ag} / \mathrm{\alpha}-\mathrm{Al}_{2} \mathrm{O}_{3}$, a series of catalysts used to manufacture acetaldehyde and formaldehyde from ethanol and methanol, respectively. The content of $\mathrm{Ag}$ in the catalyst can range from $10-40 \mathrm{wt} \%$ [2]. A large amount of spent catalysts are produced with the development of the petrochemical industry and considering the cost and potential toxicity of $\mathrm{Ag}$, they will become an important alternative resource of $\mathrm{Ag}[3,4]$. Hydrometallurgical treatment is a popular technique to recover $\mathrm{Ag}$ from these resources, in which $\mathrm{Ag}$ and other minor elements are first leached using lixiviants such as nitric acid, hydrochloric acid, and cyanide solutions.

Solvent extraction is a selective method in the hydrometallurgical treatment of metals, ranging from laboratory- to industrial-scale operations. Extraction and separation of $\mathrm{Ag}$ from nitric acid, hydrochloric acid, and cyanide solutions have been investigated using individual extractants [5-14]. Synergistic extraction systems, which are different combinations of extractants, have also been studied for increasing the extraction efficiency or improving the selectivity for Ag. 2-Hydroxy-1-Naphthaldehyde Thiosemicarbazone in the presence of organophosphorus donors (TBP, TOP, TOPO) was used to extract silver from nitric acid solution at $\mathrm{pH}$ 3.0. Synergistic enhancement factors, R, ranged from 1.9 4.7 were obtained [15].

A literature survey suggests that few efforts have been made to extract Ag with LIX84I or its mixture with acidic extractants like PC88A. In our previous experiments (unpublished) of binary mixtures of the chelate extractant, LIX84I, and various acidic extractants (PC88A, Versatic 10, D2EHPA), we found that 
adding PC88A to LIX84I could increase the efficiency of Ag extraction from nitric acid solutions. Therefore, some fundamental studies on the synergistic solvent extraction of Ag from nitric acid solutions were performed using a mixture of LIX84I and PC88A. In order to identify the extraction mechanism, the effects of some parameters, such as equilibrium $\mathrm{pH}$ and extractant concentration, were investigated. Finally, the feasibility of applying the mixture for the separation of $\mathrm{Ag}$ from nitrate solutions containing $\mathrm{Ca}, \mathrm{Si}, \mathrm{Al}$, $\mathrm{Re}$ and $\mathrm{Ni}$, is demonstrated.

\section{Experimental}

\subsection{Reagents}

2-hydroxy-5-nonyl acetophenone oxime (LIX84I, BASF, USA) and 2-ethylhexyl phosphonic acid mono-2-ethylhexyl ester (PC88A, 95\%, Daihachi, Japan) were used as-received without further treatment. Kerosene (98\%, Daejung, Korea) was used as the diluent. The Ag solution was prepared by dissolving $\mathrm{AgNO}_{3}\left(99.8 \%\right.$, Daejung, Korea) in deionized water. $\mathrm{HNO}_{3}(60 \%$, Daejung, Korea) was used to adjust the $\mathrm{pH}$ of the solution. All other reagents employed in this work were of analytical grade.

\subsection{Solvent extraction procedure}

Solvent extraction experiments were carried out by mixing equal volumes $(20 \mathrm{~mL})$ of aqueous and organic phases for 30 min using a shaker (VS-8480SF, Vision Scientific Co., LTD) at ambient temperature. Previous experiments showed 30 min was sufficient to reach equilibrium. After separation, the equilibrium $\mathrm{pH}$ value was measured with a $\mathrm{pH}$ meter (Thermo Orion Star A211). The concentration of metal ions in the aqueous phase was measured using an ICP emission spectrometer (ICPS-7500, Shimadzu). The concentration of metal ions in the organic phase was obtained by calculating the difference between the metal ion concentration in the aqueous phase before and after extraction. The distribution ratio, D, was calculated as the ratio of the concentration at equilibrium of the metal present in the organic phase to that in the aqueous phase.

\section{Results and Discussion}

\subsection{Extraction of Ag with PC88A}

Extraction of $\mathrm{Ag}$ from a nitric acid solution using PC88A as the extractant was investigated using the slope analysis method. The effect of the equilibrium $\mathrm{pH}$ on the extraction was investigated by varying the initial $\mathrm{pH}$ from 0 through 3 , while the concentrations of PC88A and $\mathrm{Ag}$ were maintained at 0.5 and $0.001 \mathrm{~mol} / \mathrm{L}$, respectively. The results are presented as a plot
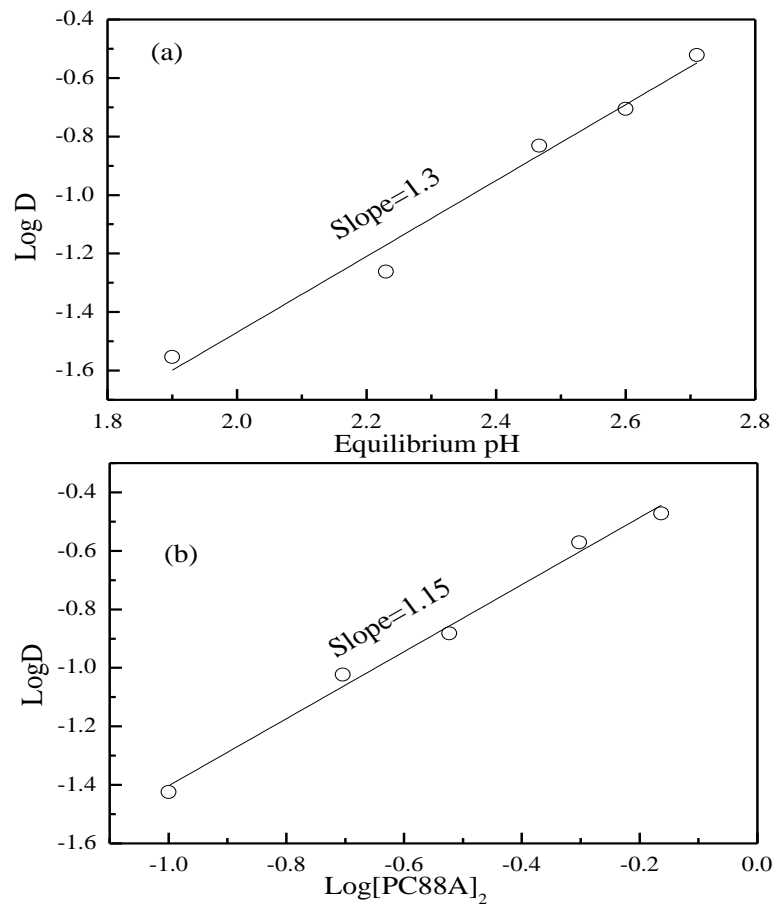

Figure 1. Extraction of Ag from nitric acid solution using PC88A as the extractant. (a) Plot of $\log \mathrm{D}$ vs. equilibrium pH. (b) Plot of $\log \mathrm{D}$ vs. $\log [\mathrm{PC} 88 \mathrm{~A}]_{2}$. 
of $\log \mathrm{D}$ vs. equilibrium pH in Figure. 1 (a).

The extraction efficiency is found to increase with increasing equilibrium $\mathrm{pH}$. The plot of $\log \mathrm{D}$ vs. equilibrium $\mathrm{pH}$ is a straight line with a slope of $1.30(\sim 1)$, indicating the release of one mole of protons from the extractant during the extraction process. The effect of the concentration of PC88A on the extraction of $\mathrm{Ag}$ was investigated by varying the concentration of PC88A in the range $0.1-0.7 \mathrm{~mol} / \mathrm{L}$ at a fixed initial $\mathrm{pH}$ of 3. The slope of the plot of $\log \mathrm{D}$ vs. $\log$ PC88A (Figure. 1(b)) is $1.15(\sim 1$ ), indicating that one mole of extractant was involved in the extraction. Since PC88A exists as a dimer [16], the extraction reaction can be represented as follows,

$$
\mathrm{Ag}^{+}+(\mathrm{HA})_{2}=\mathrm{AgA}(\mathrm{HA})+\mathrm{H}^{+}
$$

where $(\mathrm{HA})_{2}$ denotes the dimer of PC88A.

The equilibrium constant, $K$, for eq(1) can be defined as,

$$
\begin{aligned}
& K_{\text {ex }}=\left[\mathrm{AgA}(\mathrm{HA})\left[\mathrm{H}^{+}\right] /\left\{\left[\mathrm{Ag}^{+}\right]\left[\left(\mathrm{HA}_{2}\right)\right]\right\}\right. \\
& K_{\text {ex }}=\mathrm{D}\left[\mathrm{H}^{+}\right] /\left[(\mathrm{HA})_{2}\right]
\end{aligned}
$$

Where

$$
\mathrm{D}=[\mathrm{AgA}(\mathrm{HA})]\left[\mathrm{H}^{+}\right] /\left[\mathrm{Ag}^{+}\right]
$$

Taking logarithm of Eq (4),

$$
\log K=\log \mathrm{D}-\mathrm{pH}-\log \left[(\mathrm{HA})_{2}\right]
$$

The equilibrium concentration of the extractant was calculated by mass balance as follows,

$$
\left[(\mathrm{HA})_{2}\right]=\left[(\mathrm{HA})_{2}\right]_{\text {initial }}-[\mathrm{AgA}(\mathrm{HA})]
$$

The equilibrium constant was calculated by substituting the equilibrium concentration of the extractant, the value of the equilibrium $\mathrm{pH}$ and the distribution coefficients into eq.(5).

In the calculation of the equilibrium constant, the activity coefficients of the species were not considered, assuming they do not change significantly under the experimental conditions. The value of the equilibrium constant for $\mathrm{Eq}(1)$ was found to be $1.11 \times 10^{-3}$.

\subsection{Extraction of Ag with LIX84I}

Extraction of $\mathrm{Ag}$ from nitric acid solution using LIX84I as the extractant was
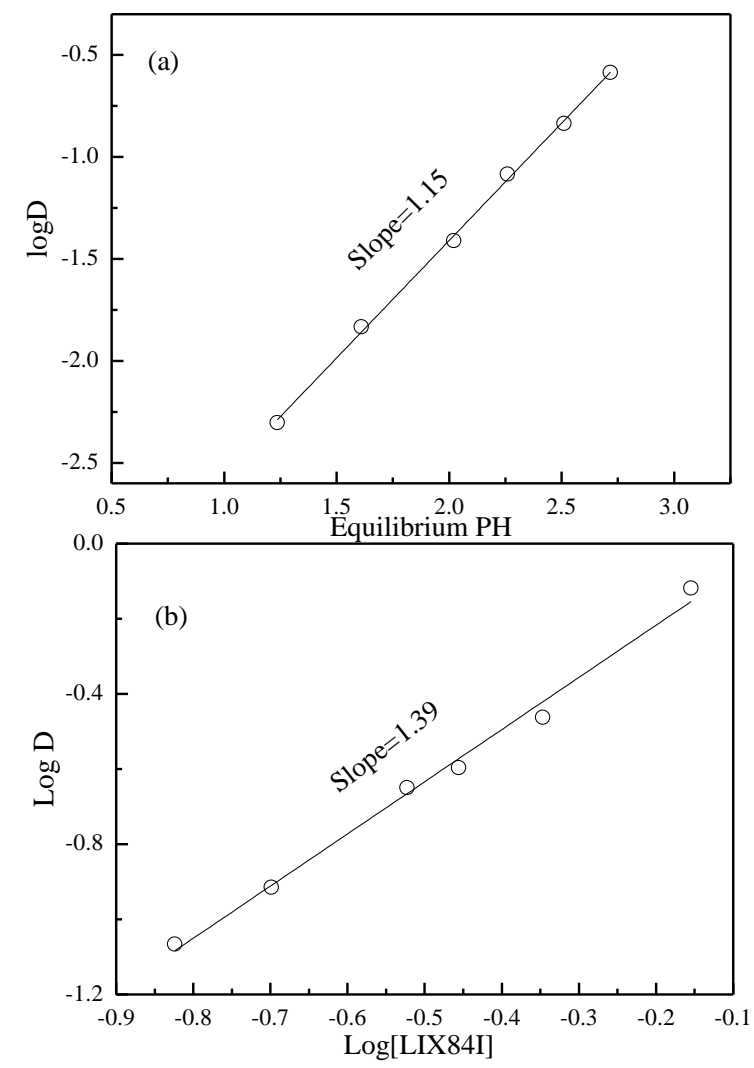

Figure 2. Extraction of Ag from nitric acid solution using LIX84I as the extractant. (a) Plot of $\log \mathrm{D}$ vs. equilibrium pH. (b) Plot of $\log \mathrm{D}$ vs. $\log [\mathrm{PC} 88 \mathrm{~A}]_{2}$. 
investigated using the slope analysis method under conditions similar to that for PC88A. The concentration of $\mathrm{Ag}$ in the feed solution was fixed at $0.001 \mathrm{~mol} / \mathrm{L}$. Figure 2 (a) represents the effect of the equilibrium $\mathrm{pH}$ value on the extraction of $\mathrm{Ag}$ from the nitric acid solution with $0.5 \mathrm{~mol} / \mathrm{L}$ of LIX84I. The extraction of $\mathrm{Ag}$ increases with increasing equilibrium $\mathrm{pH}$. The plot of $\log \mathrm{D}$ vs. the equilibrium $\mathrm{pH}$ is a straight line with a slope of $1.15(\sim 1)$, indicating the release of one mole of protons from the extractant during the extraction process. The effect of the concentration of LIX84I on the extraction of Ag was investigated by varying the concentration of LIX84I in the range $0.1-0.7 \mathrm{~mol} / \mathrm{L}$ at a fixed initial $\mathrm{pH}$ of 3. The slope of the plot of $\log \mathrm{D}$ vs. $\log$ LIX84I (Figure 2 (b)) is $1.39(\sim 1)$, indicating that one mole of extractant is involved in the extraction. The extraction reaction can be represented as follows,

$$
\mathrm{Ag}^{+}+\mathrm{HB}=\mathrm{AgB}+\mathrm{H}^{+}
$$

where HB denotes LIX84I.

The equilibrium constant of eq (7) was calculated using the same method as for Ag and PC88A. The value of the equilibrium constant for eq (7) was found to be $0.61 \times 10^{-3}$.

\subsection{Extraction of Ag with a mixture of LIX84I and PC88A}

Extraction of Ag from nitric acid solution using a mixture of LIX84I and PC88A as the extractant was investigated at an initial $\mathrm{pH}$ of 3.0. The total concentration of the binary mixture was maintained at 0.5 $\mathrm{mol} / \mathrm{L}$. The results are presented as a function of D to the mole fraction of LIX84I ( $\left.\mathrm{X}_{\mathrm{LIX84I}}\right)$ in Figure 3 . The distribution ratios of Ag using LIX84I and PC88A separately as extractants are also presented in Figure 3 for comparison. The individual extractant concentration is present at $\mathrm{x}$-axis together with the same concentration of the extractant involved in the mixed extractant.

As shown in Figure 3, the extraction of Ag with PC88A or LIX84I alone increases with increasing extractant concentration. The maximum distribution ratios for $\mathrm{Ag}$ are 0.32 and 0.30 with $0.5 \mathrm{~mol} / \mathrm{L}$ of LIX84I and $0.5 \mathrm{~mol} / \mathrm{L}$ of PC88A, respectively. In the case of the mixed extractant, the distribution ratio of Ag increases from 0.30 to 4.55 (extraction percentage: $23 \%$ to $82 \%$ ) with an increase in the mole fraction of LIX84I $\left(\mathrm{X}_{\mathrm{LIX} 84 \mathrm{I}}\right)$ from 0 to 0.8 and then decreases with a further increase in $\mathrm{X}_{\mathrm{LIX841}}$. These results clearly indicate that there is synergism at $\mathrm{X}_{\mathrm{LIX} 84 \mathrm{I}}=0.8$. The magnitude of the synergism can be expressed by the synergistic enhancement factor, $\mathrm{R}$, which is defined as,

$$
\mathrm{R}=\mathrm{D}_{\text {mix }} /\left(\mathrm{D}_{\mathrm{LIX84I}}+\mathrm{D}_{\mathrm{PC} 88 \mathrm{~A}}\right)
$$

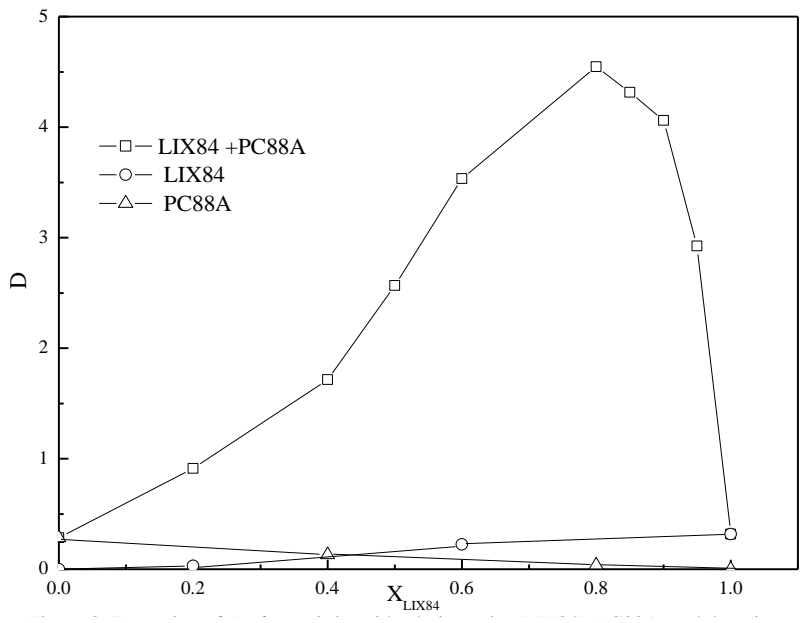

where $\mathrm{D}_{\text {mix }}$ denotes the distribution ratio of the mixture of LIX84I and PC88A, while $\mathrm{D}_{\mathrm{LIX} 84 \mathrm{I}}$ and $\mathrm{D}_{\mathrm{PC} 88 \mathrm{~A}}$ denote the distribution ratios of the individual LIX84I mol/L.) 
and PC88A solutions, respectively. For R, a value higher than 1 indicates synergistic extraction, whereas, a value lower than 1 suggests antagonism. The value of the synergistic enhancement factor obtained at a $\mathrm{X}_{\mathrm{LIX841}}$ of 0.8 is 7.34. The value of $\mathrm{R}$ for the synergistic extraction of $\mathrm{Ag}$ with 2-Hydroxy-1-Naphthaldehyde Thiosemicarbazone with TBP/ TOP/ TOPO, was $1.9 \sim 4.7$. Thus, a significant synergism with the mixture of LIX84I and PC88A is demonstrated. The enhanced extraction efficiency may be related to an increase in the hydrophobic nature of the extracted complex, which occurs by the replacement of coordinated water molecules when PC88A is added to LIX84I.

\subsection{Effect of the equilibrium $\mathrm{pH}$ value}

In order to identify the extraction mechanism for $\mathrm{Ag}$ with a mixture of $0.4 \mathrm{~mol} / \mathrm{L}$ of LIX84I and 0.1 $\mathrm{mol} / \mathrm{L}$ of PC88A, the slop

e analysis method was employed. The extraction experiments were carried out by varying the initial $\mathrm{pH}$ value of the feed solution in the range 1-3. The results are presented as a plot of $\log \mathrm{D}$ vs. equilibrium $\mathrm{pH}$ in Figure 4. The distribution ratio of $\mathrm{Ag}$ increases with increasing equilibrium $\mathrm{pH}$. The slope of the plot of $\log \mathrm{D}$ vs. equilibrium $\mathrm{pH}$ is 1.01 , suggesting that one mole of $\mathrm{H}^{+}$ions are liberated during the extraction process.

\subsection{Effect of extractant concentration}

The effect of the LIX84I concentration in the mixed extractant was investigated by varying the concentration of LIX84I in the mixture at fixed concentrations of PC88A (0.1 and $0.2 \mathrm{~mol} / \mathrm{L}$ ). The initial $\mathrm{pH}$ of the aqueous solution was 3.0. The results are shown in Figure 5 as a plot of $\log$ D vs. $\log$ [LIX84I]. The plots for both PC88A concentrations are linear and the slopes are approximately unity (1.46 and 1.35 at 0.1 and $0.2 \mathrm{~mol} / \mathrm{L}$ PC88A, respectively). Similarly, the effects of varying the PC88A concentration at fixed concentrations of LIX84I are shown in Figure 6. The plots of $\log \mathrm{D}$ vs. $\log [\mathrm{PC} 88 \mathrm{~A}]$ are linear with slopes of approximately $0.3(0.27$ and 0.28 at 0.2 and $0.3 \mathrm{~mol} / \mathrm{L}$ of LIX84I, respectively). The slope values in Figures 5 and 6 suggest that one mole of LIX84I and one mole of PC88A are involved in the extraction

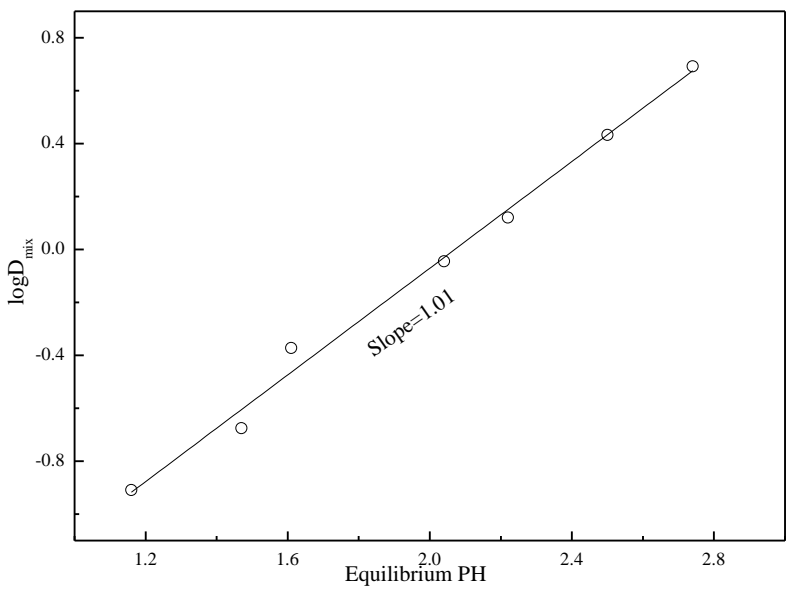

Figure 4. Effect of equilibrium $\mathrm{pH}$ on the extraction of $\mathrm{Ag}$ from nitric acid solution using the mixture of 0.4 $\mathrm{mol} / \mathrm{L}$ of LIX84I and $0.1 \mathrm{~mol} / \mathrm{L}$ of PC88A. ([Ag] $=0.001$ $\mathrm{mol} / \mathrm{L}$.)

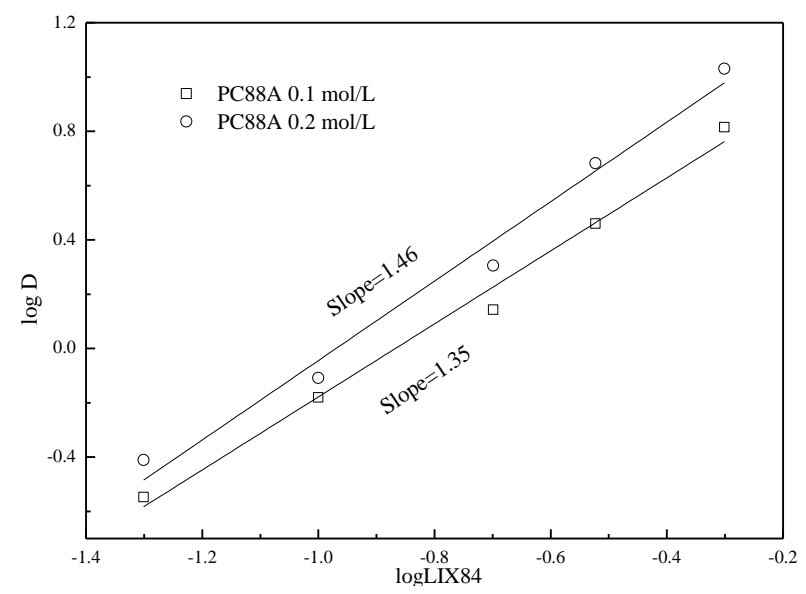

Figure 5. Effect of LIX84I concentration on the extraction of $\mathrm{Ag}$ from nitric acid solution using the mixed extractants. $([\mathrm{Ag}]=0.001 \mathrm{~mol} / \mathrm{L}$, initial $\mathrm{pH}=3$.) 

deviation from the expected slope of unity when the PC88A concentration is varied can be explained by the amount of free LIX84I available. The increase in PC88A at a fixed concentration of LIX84I results in increasing molecular interaction between the two compounds, causing the concentration of free LIX84I in the solution to be reduced. Therefore, the slope of the plot is less than the expected value of unity. The same type of phenomenon was observed in the extraction of actinides by a mixture of thenoyltrifluoroacetone (HTTA) and tributyl phosphate (TBP), [17, 18] and the extraction of Pr by a mixture of Cyanex 301 and LIX63 [19].

Considering the effects of the equilibrium $\mathrm{pH}$ and the extractant concentration, the synergistic solvent extraction of $\mathrm{Ag}$ with a mixture of LIX84I and PC88A can be represented as follows.

$$
\mathrm{Ag}^{+}+(\mathrm{HA})_{2}+\mathrm{HB}=\mathrm{AgH}_{2} \mathrm{~A}_{2} \mathrm{~B}+\mathrm{H}^{+}
$$

where $(\mathrm{HA})_{2}$ and $\mathrm{HB}$ denote the PC88A dimer and LIX84I, respectively.

The spectrophotometric data for the single LIX84 and PC88A extractants and that of their mixture are shown in Figure 7. Compared the spectrophotometric data for the mixture with that of the single extractants (PC88A/ LIX84), the decrease in intensity or disappearance of the peaks $\left(3383 \mathrm{~cm}^{-1}\right.$ and $983 \mathrm{~cm}^{-1}$ stand for $\mathrm{N}-\mathrm{H} / \mathrm{O}-\mathrm{H}, \mathrm{P}-\mathrm{OH}$, respectively) is probably due to the interaction between PC88A and LIX84I. A quantitative study will be carried out in future research.

\subsection{Separation of $\mathrm{Ag}$ from associated metal ions by a mixture of LIX84I and PC88A}

Silver is commonly associated with many of $\mathrm{Ag}$ from the nitric acid solution. The

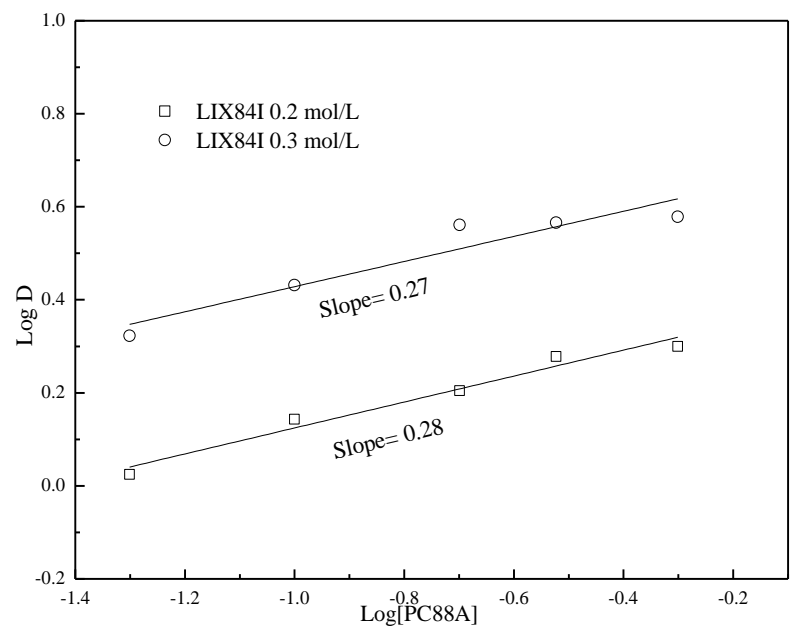

Figure 6. Effect of PC88A concentration on the extraction of $\mathrm{Ag}$ from nitric acid solution using the mixed extractants. $([\mathrm{Ag}]=0.001 \mathrm{~mol} / \mathrm{L}$, initial $\mathrm{pH}=3$. $)$

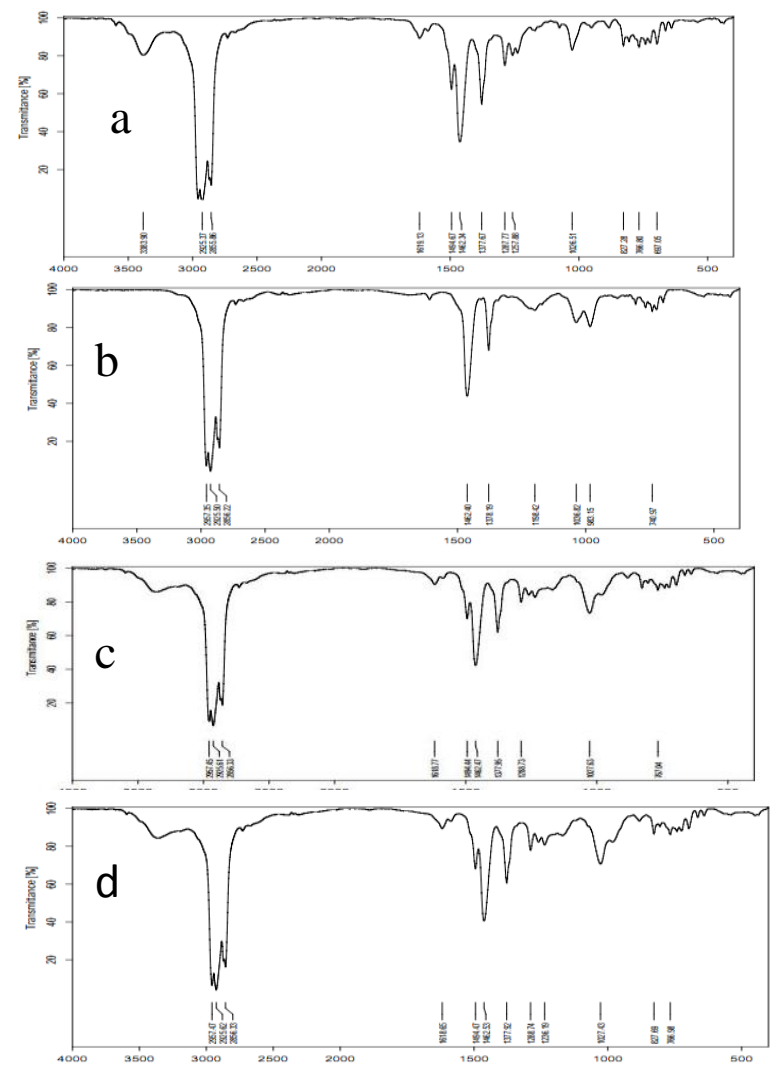

Figure 7. The spectrophotometric data. a. $0.8 \mathrm{~mol} / \mathrm{L}$ LIX84, b. $0.2 \mathrm{~mol} / \mathrm{L}$ PC $88 \mathrm{~A} \quad$ c. $0.8 \mathrm{~mol} / \mathrm{L} \mathrm{LIX} 84+$ $0.2 \mathrm{~mol} / \mathrm{L}$ PC $88 \mathrm{~A} \quad$ d. Loaded $0.8 \mathrm{~mol} / \mathrm{L}$ LIX84+ 0.2 $\mathrm{mol} / \mathrm{L} \mathrm{PC} 88 \mathrm{~A}$ metals, such as $\mathrm{Ca}, \mathrm{Si}, \mathrm{Al}, \mathrm{Re}$, and $\mathrm{Ni}$, in spent $\mathrm{Ag} / \alpha-\mathrm{Al}_{2} \mathrm{O}_{3}$ catalysts and ores. In order to explore the 
possibility of separating $\mathrm{Ag}$ from these associated metals, extraction experiments were carried out using a mixture containing 0.4 $\mathrm{mol} / \mathrm{L}$ of LIX84I and $0.1 \mathrm{~mol} / \mathrm{L}$ of PC88A. The concentration of each element in the aqueous solution was maintained at 0.001 $\mathrm{mol} / \mathrm{L}$ and the initial $\mathrm{pH}$ value of the aqueous solution was varied from 1 to 4 . As shown in Figure 8 , when the equilibrium $\mathrm{pH}$ value is higher than 1.83 (the corresponding initial $\mathrm{pH}$ value is 2), more than $80 \%$ of the $\mathrm{Ag}$ can be extracted, while extraction of the other metals is negligible. This result indicates that the mixture of LIX84I and PC88A can selectively separate Ag from the associated metals, which is of industrial importance.

\subsection{Stripping studies}

In a commercial extraction process, stripping is imperative to recover metal from the loaded organic phase. Stripping of Ag from the loaded mixture of LIX84I and PC88A was investigated using various stripping reagents (see Table 1). The loaded organic phase was obtained by shaking an aqueous solution, which had an initial $\mathrm{pH}$ of 3.0, with a mixture of $0.4 \mathrm{~mol} / \mathrm{L}$ of LIX84I and $0.1 \mathrm{~mol} / \mathrm{L}$ of PC88A (as described in the experimental section). Stripping experiments were carried out by shaking equal volumes of the loaded organic phase and stripping agent. The results are presented in Table 1. Ag can be stripped quantitatively (> $80 \%$ ) from the loaded organic phase with $\mathrm{HNO}_{3}$, a mixture of thiourea and $\mathrm{HNO}_{3}$, and $1 \mathrm{~mol} / \mathrm{L}$ of $\mathrm{Na}_{2} \mathrm{~S}_{2} \mathrm{O}_{3}$. In the case of stripping with $\mathrm{HNO}_{3}$, the stripping percentage of $\mathrm{Ag}$ increases with an increase in the $\mathrm{HNO}_{3}$ concentration and complete stripping is obtained when the concentration of $\mathrm{HNO}_{3}$ is $3 \mathrm{~mol} / \mathrm{L}$ or higher.

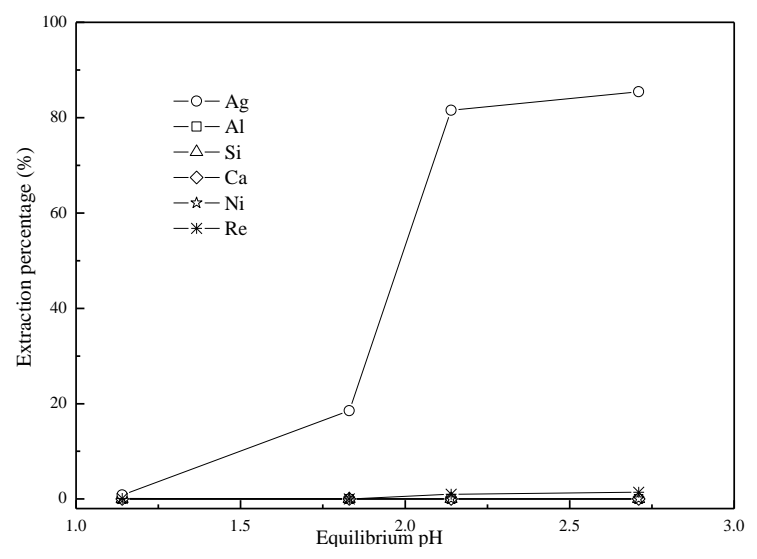

Figure 8. Effect of the equilibrium $\mathrm{pH}$ on the extraction of of $\mathrm{Ag}$ from associated metal ions using the mixture of $0.4 \mathrm{~mol} / \mathrm{L}$ of LIX84I and $0.2 \mathrm{~mol} / \mathrm{L}$ of PC $88 \mathrm{~A}$.
Table 1. Effect of different stripping reagents on the stripping (\%) of $\mathrm{Ag}$ from the loaded mixed extractant.

\begin{tabular}{|c|c|}
\hline Reagent & Stripping $(\%)$ \\
\hline $0.1 \mathrm{~mol} / \mathrm{L}$ Thiourea & 54.5 \\
\hline $0.1 \mathrm{~mol} / \mathrm{L}$ Thiourea $+0.1 \mathrm{~mol} / \mathrm{L} \mathrm{HNO}_{3}$ & 84.5 \\
\hline $0.1 \mathrm{~mol} / \mathrm{L}$ Thiourea $+0.5 \mathrm{~mol} / \mathrm{L} \mathrm{HNO}_{3}$ & 85.0 \\
\hline $0.01 \mathrm{~mol} / \mathrm{L} \mathrm{HNO}_{3}$ & 46.6 \\
\hline $0.05 \mathrm{~mol} / \mathrm{L} \mathrm{HNO}_{3}$ & 78.1 \\
\hline $0.1 \mathrm{~mol} / \mathrm{L} \mathrm{HNO}_{3}$ & 80.3 \\
\hline $0.5 \mathrm{~mol} / \mathrm{L} \mathrm{HNO}_{3}$ & 81.2 \\
\hline $1 \mathrm{~mol} / \mathrm{L} \mathrm{HNO}_{3}$ & 82.9 \\
\hline $3 \mathrm{~mol} / \mathrm{L} \mathrm{HNO}_{3}$ & 100 \\
\hline $5 \mathrm{~mol} / \mathrm{L} \mathrm{HNO}_{3}$ & 100 \\
\hline $1 \mathrm{~mol} / \mathrm{L} \mathrm{Na}_{2} \mathrm{~S}_{2} \mathrm{O}_{3}$ & 85.3 \\
\hline $25 \% \mathrm{NH}_{3} \cdot \mathrm{H}_{2} \mathrm{O}$ & nil \\
\hline $1 \mathrm{~mol} / \mathrm{L} \mathrm{NH} \mathrm{N}_{4} \mathrm{Cl}$ & 8.9 \\
\hline $1 \mathrm{~mol} / \mathrm{L}\left(\mathrm{NH}_{4}\right)_{2} \mathrm{SO}_{4}$ & 9.2 \\
\hline
\end{tabular}

\section{Conclusion}

The extraction of Ag from nitrate solutions has been studied using LIX84I and PC88A, separately, as well as in a mixture. The mixture of LIX84I and PC88A was found to show a synergistic effect on the 
extraction of Ag. The maximum value of the synergistic enhancement (7.34) was obtained at a LIX84I mole fraction of 0.8 . Based on the slope analysis results, the synergistic extraction reaction was identified and the extracted complex was proposed as $\mathrm{AgH}_{2} \mathrm{~A}_{2} \mathrm{~B}$. Complete stripping of $\mathrm{Ag}$ from the loaded mixture of LIX84I and PC88A was possible using a nitric acid solution. The mixed extractant system can be applied to separate $\mathrm{Ag}$ from nitrate solutions containing $\mathrm{Ca}, \mathrm{Si}, \mathrm{Al}, \mathrm{Re}$, and $\mathrm{Ni}$, which is important in practical separations.

\section{Acknowledgement}

This research was supported by the Basic Science Research Program through the National Research Foundation of Korea (NRF) funded by the Ministry of Education (No: 2014R1A1A2007063). The authors would like to express their thanks for the financial support. The Gwangju Green Environment Center (No. 06-2-70-73) is also gratefully acknowledged.

\section{References}

1) A. Sari, M. Tüzen, Micropor. Mesopor. Mater, 170, 155-163 (2013).

2) M. Zhang, X. Jiang, J. Shi, G. Zhao, G. Yin, Y. Zhang, Q. Shi and Z. Liu, Sino-Global Energy, 15, 90-98 (2010).

3) A. Fornalczyk, J. achievements, J. Achiev. Mater. Manuf. Eng., 55, 864-869 (2012)

4) A. M. Sastre, A. Kumar, F. J. Alguacil, J. Chem. Technol. Biotechnol., 79, 306-310 (2004).

5) M. S. Alam, K. Inoue, K. Yoshizuka, Y. Dong, P. Zhang, Hydrometallurgy, 44, 245-254 (1997).

6) O. Ortet, A. P. Paiva, Sep. Sci. Technol., 45, 1130-1138 (2010).

7) S. Kedy, F. Kandil, N. Almhna, J. Chin. Chem. Soc., 59, 1-5 (2011).

8) F. Xie, D. Lu, H. Yang, D. Dreisinger, Miner. Process. Extr. Metall. Rev., 35, 229-238 (2014)

9) Y. Baba, Y. Umezaki, K. Inoue, J. Chem. Eng. Jpn., 19, 27-30 (1986).

10) Y. I. Lee, S. H. Park, J. S. Kim, D. W. Kim, K. Y. Choi, Bull. Korean Chem. Soc., 20, 487-490 (1999).

11) K. Ohto, E. Murakami, T. Shinohara, K. Shiratsuchi, K. Inoue, M. Iwasaki, Anal. Chim. Acta., 341, 275-283 (1997).

12) K. C. Sole, T. L. Ferguson, J. B. Hiskey, Solvent Extr. Ion Exch., 12, 1033-1050 (1994).

13) V. Stankovic, L. Outarra, F. Zonnevijlle, Ch. Comninellis, Sep. Purif. Technol., 61, 366-374 (2008).

14) L. E. Elin, A. Emma, E. Christian, F. Mark, S. Gunnar, H. Zuzana, G. Bohumír, Procedia Chem., 7, 239-244 (2012).

15) D. Pulak, B. Sukalyan, Int. J. Chem. Tech. Res., 3, 1349-1358 (2011).

16) A. K. De, S. M. Khopkar, R. A. Chalmers, Solvent Extraction of Metals, Van Nostrand Reingold, London, 1970, pp 158-200.

17) P. K. Khopkar, J. N. Mathur, J. Radioanal. Chem., 60, 131-140 (1980).

18) P. K. Khopkar, J. N. Mathur, Sep. Sci. Technol., 16, 957-969 (1981).

19) B. N. Kumar, H. S. Jeon, M. S. Lee, J. Ind. Eng. Chem., in press. (2014). 